\title{
Resenha do livro Psicoterapia interpessoal: guia prático do terapeuta
}

\author{
Review of the book Clinician's Quick Guide to Interpersonal Psychotherapy
}

\author{
Marcos Hirata Soares ${ }^{1}$ \\ ${ }^{1}$ Mestre, Docente, Centro de Ciências da Saúde, Departamento de Enfermagem da Universidade Estadual de Londrina (UEL), Londrina, PR. \\ Este trabalho foi realizado no Centro de Ciências da Saúde, Departamento de Enfermagem da Universidade Estadual de Londrina (UEL), Londrina, PR.
}

\section{Resumo}

O livro é direcionado aos diversos profissionais que atuam na assistência em saúde mental e, segundo seu prefácio, a obra é resultado de 3 décadas de desenvolvimento de um método de tratamento psicoterapêutico, inicialmente para depressão maior, denominado psicoterapia interpessoal (TIP); posteriormente, passou a ser aplicado em outros transtornos psiquiátricos complexos, como o transtorno de personalidade borderline. A obra tem o objetivo de ser um guia de fácil leitura e consulta, descrevendo os métodos de abordagem e condução dos casos clínicos, mas já partindo do pressuposto de que os profissionais (leitores) possuem conhecimento e habilidade nos fundamentos da psicoterapia e no manejo de pessoas com diagnósticos como transtornos do humor ou ansiedade, por exemplo. Cabe aqui frisar que embora não haja referência a nenhuma obra de Carl Rogers, considerado o precursor do relacionamento interpessoal como recurso pedagógico e psicoterapêutico, esta obra apresenta enorme semelhança com a teoria desse autor, mas não em relação às indicações a determinados transtornos como os do humor, as quais são feitas de forma completa, também especificando em cada contexto a abordagem a ser usada. O livro é muito bem elaborado, tanto do ponto de vista didático como científico, ou seja, é um livro de fácil leitura e compreensão e com referências a artigos de periódicos de grande relevância no meio acadêmico e científico.

Descritores: Psicoterapia breve, assistência em saúde mental, relações interpessoais.

\begin{abstract}
This book is aimed at those professionals who provide mental health services. According to its preface, it was written based on a method of psychotherapeutic treatment developed over a 30-year period and called interpersonal psychotherapy (IPT). This method was initially aimed at major depression, but later it was adapted to other complex psychiatric disorders such as borderline personality. The objective of this work was to be an easy to read quick reference book, providing descriptions of the methods used to approach and manage clinical cases, based on the assumption that professionals (readers) have knowledge of psychotherapy and skills to manage people diagnosed with mood or anxiety disorders. It is worth emphasizing that although none of the works by Carl Rogers are mentioned in this book, its content is very similar to Rogers's theory, except for the section regarding mood disorders, which is addressed in a thorough manner, including the approach to be used within each context. Rogers is considered to be the pioneer in the use of interpersonal relationship as a pedagogical and psychotherapeutic resource. The book was very well written, considering both the didactic and scientific point of view, that is, it is easy to read and understand, mentioning articles published in very important journals for the scientific and academic community.
\end{abstract}

Keywords: Short psychotherapy, mental health care, interpersonal relationships.

\section{Correspondência:}

Marcos Hirata Soares, Av. Robert Koch, 60, CCS - Departamento de Enfermagem. Vila Operária, CEP 86038-350, Londrina, PR. E-mail: mhirata@uel.br Não foram declarados conflitos de interesse associados à publicação deste artigo.

Copyright (C) Revista de Psiquiatria do Rio Grande do Sul - APRS

Recebido em 09/10/2009. Aceito em 23/10/2009. 


\section{Resenha}

Editada originalmente no idioma inglês em 2007, a obra "Psicoterapia interpessoal: guia prático do terapeuta" foi lançada em 2009 pela editora Artmed. O livro é direcionado aos diversos profissionais que atuam na assistência em saúde mental, e, segundo seu prefácio, a obra é resultado de 3 décadas de desenvolvimento de um método de tratamento psicoterapêutico, inicialmente para depressão maior, denominado psicoterapia interpessoal (TIP). Posteriormente, esse método foi também aplicado em outros transtornos psiquiátricos complexos como o transtorno de personalidade borderline.

A obra tem o objetivo de ser um guia de fácil leitura e consulta, descrevendo os métodos de abordagem e condução dos casos clínicos, mas já partindo do pressuposto de que os profissionais (leitores) possuem conhecimento e habilidade nos fundamentos da psicoterapia e no manejo de pessoas com diagnósticos como transtornos do humor ou ansiedade, entre outros.

Os autores também apontam que a TIP pode ser utilizada com ou sem medicação, bem como ser ensinada a pessoas menos treinadas. A maior aplicação da TIP ocorre em casos de transtornos do humor em diversas fases da vida dos pacientes, como gravidez, adolescência ou idade avançada. Nesses casos, a TIP é uma das psicoterapias recomendadas pela Associação Americana de Psiquiatria.

Quanto a sua fundamentação teórica, na TIP a depressão é conceituada como tendo causas múltiplas, sendo os sintomas associados geralmente a algum evento da vida da pessoa. Da perspectiva da TIP, o quadro da depressão é constituído por sintomas, fatores ligados à vida social e interpessoal e pela personalidade. Dessa forma, entender o contexto interpessoal, ou seja, os problemas do "aqui e agora" do paciente é o ponto principal da TIP; também, como são focadas as pessoas importantes na vida do paciente ao momento do transtorno ajuda para que ele possa avaliar a sua vida nesse momento, bem como seus afetos, e ajuda para que ele possa ter domínio do seu contexto de vida.

Os autores esclarecem ainda que a TIP não tem como objetivo buscar as origens e explicações de sentimentos negativos ou comportamentos do paciente, realizar uma análise da infância ou uma interpretação dos sonhos, mas visa ajudar a pessoa a entender a si mesma de uma maneira mais profunda ao auxiliá-lo na exploração das opções e no desenvolvimento de recursos para interagir com o meio externo de maneira produtiva e satisfatória.

Em no máximo três encontros, a tarefa do terapeuta consiste na realização do diagnóstico mediante a análise da história clínica e o uso de escalas psicométricas. A partir da definição, o terapeuta prossegue com a psicoeducação, explicando sobre o problema de saúde apresentado, assim como esclarecendo os mitos sobre a doença do paciente. Da perspectiva da
TIP, as principais situações problema são o luto, a disputa de papéis e a transição e os déficits interpessoais.

Ao estabelecer o diagnóstico e identificar os problemas interpessoais do paciente, inicia-se o processo de formulação do tratamento, no qual o terapeuta apresenta as informações obtidas em relação aos sintomas pela história clínica e os eventos de vida relacionados com a depressão, propondo um prazo de terapia, os resultados esperados e como a pessoa poderá obter melhora de sua doença. O terapeuta estabelecerá um contrato de tratamento com o paciente.

$\mathrm{Na}$ etapa seguinte, denominada de intermediária, iniciase a terapia pela busca de informações sobre os últimos fatos acontecidos, a relação destes com o contexto interpessoal e o grau em que eles afetaram o paciente. Essa sequência é a parte central da intervenção em TIP. O terapeuta enfoca o humor e a interação interpessoal, ajudando o paciente a perceber a ligação entre eles e a ficar à vontade com novas estratégias que visam um melhor funcionamento psicossocial.

O tempo gasto na terapia é usado para a discussão dos sentimentos e a tomada de atitudes para mudar o tipo de percepção dos sentimentos do paciente. Para tanto, são utilizadas algumas técnicas, como a exploração não diretiva, a evocação direta, o encorajamento do afeto, clarificação, análise da comunicação e das decisões, role-play e a própria relação interpessoal. Além disso, em outros capítulos, a obra traz a abordagem quando a situações de luto, disputas interpessoais, transições de papéis e déficits interpessoais envolvidos no contexto da depressão.

Sobre o final da terapia, considera-se que o tempo mínimo é de seis sessões, uma vez por semana, podendo durar até 36 sessões mensais, tendo como meta, entre outras, o fortalecimento do senso de competência e independência e a discussão da continuidade do tratamento por outros meios, como um tratamento psiquiátrico, caso persistam os sintomas, ou, ainda, o encaminhamento para outra forma de psicoterapia.

Cabe aqui frisar que embora não haja no livro que nos ocupa referência a nenhuma obra de Carl Rogers, considerado o precursor do relacionamento interpessoal enquanto recurso pedagógico e psicoterapêutico, verifica-se nele uma enorme semelhança com a teoria desse autor; porém, essa similitude não diz respeito às indicações a determinados transtornos como os do humor, as quais são feitas de forma completa, também especificando em cada contexto a abordagem a ser usada.

O livro é muito bem elaborado, tanto do ponto de vista didático como científico, ou seja, é um livro de fácil leitura e compreensão e com referências a artigos de periódicos de grande relevância no meio acadêmico e científico.

\section{Referências}

1. Weissman MM, Markowitz JC, Klerman GL. Psicoterapia Interpessoal: guia prático do terapeuta. Porto Alegre: Artmed; 2009. 